\title{
The validity of the Menopause-specific Quality of Life questionnaire in women with type 2 diabetes
}

\author{
S. S. Hasan, K. Abmadi*, R. Santigo* and S. I. Abmed"
}

The University of Queensland, Woolloongabba, Queensland, Australia; *International Medical University, Bukit Jalil, Kuala Lumpur, Malaysia

Key words: VALIDITY, MENOPAUSE, QUALITY OF LIFE, DIABETES

\begin{abstract}
Objectives To examine the validity and reliability of the Menopause-specific Quality of Life (MENQOL) questionnaire in a sample of women with diabetes in Malaysia, with the secondary aim of determining whether MENQOL domain scores were associated with depression and diabetes.

Methods A total of 337 postmenopausal women (241 with diabetes, 96 controls) were evaluated. Construct validity was evaluated using principal components analysis (PCA) and comparing scale items against the mental component score of the Short Form-12 (SF-12 MCS), and against the Center for Epidemiologic Studies Depression Scale 10 (CES-D 10). Consistency assessment was conducted using Cronbach's $\alpha$.

Results The internal consistencies for the physical (PHS), psychosocial (PS), sexual (VSS) and vasomotor domains were $0.86,0.79,0.79$ and 0.70 , and 0.90 for the full scale of MENQOL. PCA revealed a fourfactorial model. Diabetes and non-diabetes subjects experienced their first period (13.25 vs. 13.10 years, $p=0.680)$ and achieved menopause around the same age (49.35 vs. 48.87 years, $p=0.426)$. We found significant variations in the MENQOL's PHS and PS domain scores that could be explained by SF-12 PCS (25\%) and SF-12 MCS (20\%) sub-scales. The validity of the MENQOL domains was demonstrated through significant associations with the equivalent SF-12 MCS and PCS subscales. The PS domain of the MENQOL also predicted the likelihood of symptoms of depression (1.42, 95\% confidence interval 1.01-2.02).

Conclusions This study confirms the validity and internal consistency of the MENQOL questionnaire for measuring quality of life in postmenopausal women with diabetes, suggesting that the instrument can be used to screen people for menopausal symptoms.
\end{abstract}

\section{INTRODUCTION}

Being one of the leading causes of death globally, type 2 diabetes mellitus prevails across both genders; however, its prevalence and complications increase among women aged 65 years and older ${ }^{1,2}$. In Malaysia, up to 1.2 million individuals are experiencing diabetes, out of which more than half are undiagnosed $^{3}$. Moreover, with an alarming and colossal increase, within a decade, the prevalence of diabetes has drastically risen from $8.3 \%$ in 1996 to $14.9 \%$ in $2006^{3,4}$. In 2010, of the Malaysians diagnosed with diabetes, $11.6 \%$ were women and this figure is speculated to reach a height of $13.8 \%$ in the year $2030^{5}$. Furthermore, a higher prevalence of type 2 diabetes has been reported among women with a history of menstrual irregularity ${ }^{6}$, particularly in those with long and highly irregular menstrual cycles ${ }^{7}$.

Diabetes has detrimental effects on health outcomes ${ }^{8}$ and its personal and social predicaments are well studied ${ }^{9,10}$. For instance, studies have shown significant negative associations between quality of life and progression of disease in different populations, for example, elderly women ${ }^{9,10}$. Clearly, it is important to be able to examine quality of life accurately in postmenopausal women with diabetes. In general, women in the transition phase, i.e. perimenopausal phase or those who have already achieved menopause, experience more menopausal symptoms compared to premenopausal women

Correspondence: Dr S. S. Hasan, The University of Queensland, 20 Cornwall Street, Woolloongabba, 4I02, Queensland, Australia; E-mail: shahzad. syed@uqconnect.edu.au 
in terms of frequency and severity. Specifically, women in the perimenopausal and postmenopausal years experience significantly more vasomotor, sexual and psychosocial symptoms compared to women in the premenopausal years ${ }^{11-13}$.

Menopausal symptoms as measured by the Menopausespecific Quality of Life (MENQOL) questionnaire in postmenopausal women have a negative impact on health-related quality of life ${ }^{14}$. The 29-item MENQOL questionnaire ${ }^{15}$ has been widely used in different populations ${ }^{11,16-20}$. This tool captures the health-related quality of life in four domains, i.e. vasomotor, physical, psychosocial, and sexual functioning ${ }^{15}$. Additionally, the psychometric properties, detailed factorial analysis and validation of the MENQOL instrument in older women (>60 years) have been reported using a Western non-diabetes population ${ }^{21,22}$.

Interestingly, there is a commonality among some of the postmenopausal symptoms and those reported by individuals diagnosed with diabetes. The MENQOL questionnaire contains some items that could be confounded with the symptoms of poorly controlled diabetes. These symptoms are, and not limited to, depression, anxiety, and sleep problems ${ }^{23-26}$. Questions relating to symptoms such as frequent urination and lack of energy (which may also be related to symptoms of diabetes) are also included in the MENQOL scale ${ }^{23-26}$.

It seems that there is dearth of data on the validity of measuring these symptoms in a menopausal population with diabetes. Moreover, variations in reported symptoms between Asian and Caucasian women have been well established, where Asian women suffer less vasomotor and psychological symptoms than Western women ${ }^{11,18-20}$. However, little is known about symptoms experienced by menopausal women with diabetes, particularly those living in the Asia-Pacific region.

Although the MENQOL questionnaire has been administered in women with type 2 diabetes mellitus in Nigeria ${ }^{27}$, and those at risk of metabolic syndrome in Ecuador ${ }^{17}$, this is the first study to validate the MENQOL questionnaire using postmenopausal women, with and without diabetes in Malaysia. We are interested to determine whether MENQOL could be used to examine quality of life in postmenopausal women with diabetes. We explored both the validity of the MENQOL domains and their association with symptoms of depression in a sample of women with diabetes in Malaysia.

\section{MATERIALS AND METHODS}

\section{Study design and population}

In this case-control study, we recruited women aged 35-75 years with type 2 diabetes mellitus (case) and matched them with women without type 2 diabetes (control) in the same age range. Each case was a woman with a known diagnosis of diabetes; and subsequently the control was a woman with no known diagnosis of diabetes. The diagnosis of diabetes or absence of diabetes was confirmed by medical records. Menopausal status was identified as premenopausal (no irregular periods in the previous 12 months), perimenopausal (irregular periods for less than 12 months), or postmenopausal (cessation of menses for 12 months or longer). Since MENQOL is validated only in a postmenopausal population, MENQOL assessment was restricted to postmenopausal women only.

Women with diabetes were recruited from outpatient clinics at PutraJaya Hospital in PutraJaya, Tuanku Jaa'far Hospital and Seremban Health Clinic, both in Negeri Sembilan, one of the states of Peninsular Malaysia. The control subjects were healthy friends or unrelated family members with no blood relationship, for example, inlaws of people with diabetes.

The study was conducted according to the principles expressed in the Declaration of Helsinki and was approved by the School of Pharmacy Ethics Committee at the International Medical University Research and Ethics Committee (Project ID No: B01/09-Res (04) 2012). The study was also registered with the National Medical Research Registry (NMRR), Ministry of Health Malaysia.

\section{Procedures and measures}

Data on diabetes were collected through a self-administered questionnaire, where women were asked 'Have you EVER been told by a doctor that you have diabetes (high blood sugars)?', with response options 'yes' or 'no'. Subjects were categorized as having diabetes if they had been told by a physician that they had diabetes. This information was further confirmed by patients' medication records, fasting plasma glucose $\geq 7.0 \mathrm{mmol} / \mathrm{l}$, and random plasma glucose greater than or equal to $11.1 \mathrm{mmol} / \mathrm{l}$. Subjects were not recruited if data on their fasting glucose levels were missing.

Women participating in this study were assessed for depressive symptoms using the Center for Epidemiologic Studies Depression Scale (CES-D), 10-item and for quality of life using the Outcomes Survey Short Form (SF), 12-item scales.

\section{Construct validity of MENQOL domains}

We assessed the validity of the MENQOL domains against the presence or absence of diabetes. We also examined the differences in the symptoms commonly reported in both diabetes and postmenopause. We determined the degree to which presence or absence of diabetes was related to quality of life on the MENQOL domains, as individuals with diabetes are linked to significant decrements in dimensions of quality of life $e^{8,28}$.

The MENQOL is a validated instrument used to measure quality of life and is able to capture not only the existence of frequent menopausal symptoms, but also the extent to which the symptom(s) is/are bothersome ${ }^{15,21}$. For analyses, we scored the items from 1 to 8 in the following manner: (1) The subject responded 'No', she did not experience the problem; (2) the subject experienced the problem and rated it as ' 0 ' on the bothered scale; (3) the subject experienced the problem and rated it as ' 1 ' on the bothered scale; (4) rated as ' 2 '; (5) rated 
as ' 3 '; (6) rated as ' 4 '; (7) rated as ' 5 '; (8) rated as ' 6 '. Each domain score ranges from 1 to 8 ; ' 1 ' implies good health and ' 8 ' implies poor health ${ }^{15,21}$.

We re-validated the MENQOL psychosocial and physical domains against the Short Form (SF-12) instrument, a validated and generic measure of health status that assesses both physical and mental quality of life ${ }^{29-31}$. SF-12 is a multipurpose survey instrument comprising 12 questions, developed as a legitimate alternative to the SF-36. The two summary scales, the Mental (MCS) and the Physical Component Summary (PCS), provide an insight into mental and physical health ${ }^{32}$. As described elsewhere ${ }^{32,33}$, the MCS score assessing impact of health on mental health function was calculated. The MCS includes subscales that measure vitality (VT), social function (SF), mental health $(\mathrm{MH})$, and role functionemotional (i.e. the extent to which one's emotional problems limit one's role function, RE). The PCS includes subscales that measure physical functioning $(\mathrm{PF})$, role physical (RP), bodily pain (BP), and general heath $(\mathrm{GH})$. The scores were calculated using the scores of the questions that range from 0 to 100 ; ' 0 ' implies poor health and ' 100 ' implies good health. Unlike the MENQOL domains, higher SF-12 component scores represent better quality of life. We assessed the validity of the MENQOL's sexual domain indirectly against marital status. The rationale behind this indirect validation is described elsewhere 22,34 .

We also examined the degree to which depression symptoms were associated with quality of life on the MENQOL psychosocial domain. CES-D 10, a screening tool for depressive symptoms ${ }^{35}$, has been used in people with diabetes ${ }^{36}$ and was now used to assess depression symptoms. The shorter form contains ten depression items and is easier and quicker to administer in clinical and non-clinical settings. It has been shown to have reliability and validity comparable to the standard 20-item CES-D instrument and is considered a good instrument for screening depression in patients with diabetes $^{36}$. The CES-D 10 uses a 0-3 response scale, with total symptom severity scores ranging from 0 (no depression) to 30 (severe depression) ${ }^{37}$. Participants in this study were categorized as depressed if they scored 11 or more on the CES-D 10 scale. Higher scores on the MENQOL indicate a poorer quality of life. Higher scores on the CES-D indicate greater depression symptoms.

\section{Statistical analysis}

The data were analyzed using the Statistical Package for Social Sciences (SPSS) ${ }^{\circledR}$ version 20 and STATA IC ${ }^{\circledR}$ version 12, with a significance level of $\leq 0.05$. Descriptive statistics were used to calculate percentage frequencies, means and standard deviations. Since MENQOL had not been previously validated in a sample of women with diabetes, we conducted a principal component analysis (PCA) to examine the underlying components or domains of MENQOL. In order to achieve a favorable ratio $(>10: 1)$ of respondents over instrument items, a minimum of 200 participants was required to conduct factor analysis. Next we performed the Kaiser-Meyer-Olkin test $(\mathrm{KMO})$ to measure sampling adequacy of $>0.7$. An eigenvalue $>1$ was used for retaining factors in PCA. However, there are chances of potential biases that can be introduced by the use of a cut-off value $>1$. Therefore, we inspected the Scree plot, as a superior factor selection method to determine the appropriate number of factors to retain for rotation. Bartlett's test of sphericity was used to measure significant correlations between variables. The corrected item-total score correlations were also examined. Reliability of MENQOL items and domains were assessed using Cronbach's $\alpha$ and intra-class correlation coefficients, where an $\alpha$ of $0.70-0.90$ was considered good.

The independent $t$-test was applied to obtain the mean (95\% confidence interval) and statistical differences between mean MENQOL symptoms and domain scores (continuous variable) and diabetes (categorized as 'yes' or 'no'). To validate the MENQOL physical and psychosocial domains against the SF-12 physical and mental component summary scores, linear regression was used. Age was included as a covariate (continuous variable) in the regression analyses to control for potential confounding effects. Education and diabetes were included as covariates to control for potential effects on quality of life ${ }^{8-10,38}$. Age, education and diabetes were included as covariates in all linear and logistic regression analysis used in this study. Linear regression was also used to validate the sexual domain with marital status. Finally, logistic regression analysis determined the degree to which depression symptoms and diabetes were associated with quality of life on the MENQOL domains.

\section{RESULTS}

\section{Sociodemographic characteristics}

Out of total of 640 participants, half $(n=320)$ were identified as 'case' while the remaining half $(n=320)$ were identified as 'control'. The overall mean age was 57.43 years, standard deviation \pm 6.28 years. The mean age at diabetes diagnosis was $47.75 \pm 9.81$ years, with all receiving oral hypoglycemic drugs and/or insulin. Diabetes subjects were older than control subjects (60.22 vs. 54.64 years). The majority of the women were Malay and had attained secondary education. Women with diabetes were mostly homemakers with no paid jobs and no monthly income, while control subjects were mostly government or non-government employees, working $41 \mathrm{~h}$ or more per week with a monthly income of less than RM 3500.

Both 'case' and 'control' subjects experienced their first period around the same age (mean age 13.25 vs. 13.10 years, $p=0.680$ ). Similarly, they achieved menopause around the same age (mean age 49.35 vs. 48.87 years, $p=0.426$ ). Regarding menopausal status, more diabetes subjects had attained menopause compared to control subjects $(37.7 \%$ vs. $15.0 \%$, $p=0.001)$. However, more control subjects had perimenopausal status compared to women with diabetes $(11.2 \%$ vs. 
Table 1 Descriptive statistics of issues related to reproduction, by case and control $(n=640)$. Data are given as mean \pm standard deviation or $n(\%)$

\begin{tabular}{lccc}
\hline & Diabetes & Control & $p$ Value \\
\hline $\begin{array}{l}\text { Age at time of study } \\
\quad \text { years) }\end{array}$ & $60.22 \pm 7.07$ & $54.64 \pm 5.49$ & 0.001 \\
$\begin{array}{l}\text { Age at last pregnancy } \\
\quad \text { years) }\end{array}$ & $27.53 \pm 4.32$ & $29.41 \pm 3.28$ & 0.001 \\
$\begin{array}{l}\text { Age at menopause (years) } \\
\text { Age when periods started }\end{array}$ & $49.35 \pm 5.19$ & $48.87 \pm 4.16$ & 0.426 \\
$\quad 13.25 \pm 3.27$ & $13.10 \pm 1.37$ & 0.680 \\
$\quad$ yumbers) & $4.15 \pm 1.93$ & $3.64 \pm 1.94$ & 0.001 \\
$\begin{array}{l}\text { Menopausal status } \\
\text { Premenopausal }\end{array}$ & $63(9.8 \%)$ & $152(23.7 \%)$ & 0.001 \\
$\begin{array}{l}\text { Perimenopausal } \\
\text { Postmenopausal }\end{array}$ & $16(2.5 \%)$ & $72(11.2 \%)$ & 0.001 \\
\hline
\end{tabular}

$2.5 \%, p=0.001)$. Diabetes subjects had a higher number of pregnancies compared to control subjects (mean 4.15 vs. 3.64, $p=0.001$ ) (Table 1).

\section{Score distributions}

There were small 'floor' effects for all domains and the total score. However, there was a modest amount of 'ceiling' effect, particularly in vasomotor and sexual domains, as shown in Table 2.

\section{PCA and reliability}

The 29 items of MENQOL were entered into an iterated PCA with Kaiser normalization. The KMO test of sampling adequacy was applied prior to factor extraction, which resulted in an overall index of 0.95 , suggesting that the sample was adequate for factor analysis. Inspection of the corresponding Scree plot and identification of an 'elbow' point, after which the inclusion of additional factors does not result in substantial gains in variance explained, yielded the existence of four factors, with eigenvalues more than one. The non-rotated factor produced the most explanation of the data and excellent loadings.

Reliability coefficients were constructed for each domain of the MENQOL. Cronbach's $\alpha$ statistics were acceptable for each of the domains (Table 2). The values for the physical, psychosocial, sexual and vasomotor domains were $0.86,0.79$, 0.79 and 0.70 , respectively and 0.90 for the full scale of MENQOL. The Cronbach's $\alpha$ values of MENQOL domains were almost comparable for diabetes and control subjects.

\section{Construct validity}

Since MENQOL is only validated in a postmenopausal population, MENQOL assessment was restricted to postmenopausal women only (241 cases, 96 controls). Table 3 displays the results of the linear regression analysis of the validation instruments including covariates on MENQOL psychosocial and physical domains. Our results indicated that better quality of life on the SF-12 physical and mental component scores was significantly related to better quality of life on the physical (correlation coefficient $=0.497$ ) and psychosocial (correlation coefficient $=0.436$ ) domains of the MENQOL.

When the SF-12 mental component score increased by one unit, the MENQOL psychosocial domain score decreased by 0.029 units. Performance on the SF-12 mental component accounted for $20 \%$ of the variance in the MENQOL psychosocial domain scores. When the SF-12 physical component score increased by one unit, the MENQOL physical domain score decreased by 0.026 units. Performance on the SF-12 physical component accounted for $25 \%$ of the variance in the MENQOL physical domain scores.

When age increased by 1 year, the scores for MENQOL vasomotor domain $(p=0.699)$, psychosocial domain $(p=0.444)$, physical domain $(p=0.442)$, and sexual domain $(p=0.394)$ decreased by $0.005,0.008,0.007$, and 0.010 units, respectively. The association between SF-12 summary scales and MENQOL domains remained significant after adjusting for age, education, and diabetes. The logistic regression analysis showed that MENQOL vasomotor, physical, and sexual domains actually decreased by small amounts, 0.099 (95\% CI -0.463-0.264), 0.185 (95\% CI -0.479-0.109), and 0.048 (95\% CI $-0.388-0.293)$, for women with diabetes. The effects on the psychosocial domain (increased by 0.310 )

Table 2 Values of Cronbach's $\alpha$ and scores of participants with diabetes, by domains of the Menopausespecific Quality of Life (MENQOL) questionnaire $(n=241)$

\begin{tabular}{|c|c|c|c|c|c|}
\hline $\begin{array}{l}\text { MENQOL } \\
\text { domain }\end{array}$ & Cronbach's a & $\begin{array}{l}\text { Mean } \pm \\
\text { standard } \\
\text { deviation }\end{array}$ & Median & $\begin{array}{c}\text { 'Floor' effects } \\
\text { (worst health score) } \\
n(\%)\end{array}$ & $\begin{array}{c}\text { 'Ceiling' effects } \\
\text { (best health score) } \\
n(\%)\end{array}$ \\
\hline Vasomotor & 0.70 & $1.98 \pm 1.25$ & 1.33 & $0(0.0)$ & $63(26.14)$ \\
\hline Psychosocial & 0.79 & $2.44 \pm 1.38$ & 2.00 & $1(0.41)$ & $20(8.30)$ \\
\hline Physical & 0.86 & $2.85 \pm 1.29$ & 2.69 & $0(0.0)$ & $6(2.49)$ \\
\hline Vaginal sexual & 0.79 & $1.53 \pm 1.25$ & 1.00 & $0(0.0)$ & 75 (31.12) \\
\hline Total (full scale) & 0.90 & $2.53 \pm 1.09$ & 2.38 & $0(0.0)$ & $0(0.0)$ \\
\hline
\end{tabular}


Table 3 Results of linear regression analyses with the Menopause-specific Quality of Life (MENQOL) domains as the dependent variables and the SF-12 component scores, marital status, age, education, and diabetes as independent variables $(n=337)$

\begin{tabular}{|c|c|c|c|c|c|}
\hline & $\begin{array}{l}\text { Parameter } \\
\text { coefficients }\end{array}$ & p Value & $\begin{array}{c}95 \% \text { confidence } \\
\text { interval }\end{array}$ & Variance $R^{2}$ & $\begin{array}{l}\text { Correlation } \\
\text { coefficients }\end{array}$ \\
\hline \multicolumn{6}{|c|}{ Vasomotor domain (VS) } \\
\hline Age & -0.005 & 0.699 & $-0.028-0.019$ & 1.0 & Age: $\mathrm{VS}=-0.052$ \\
\hline Diabetes* & -0.099 & 0.591 & $-0.463-0.264$ & & \\
\hline Education $^{\dagger}$ & 0.088 & 0.630 & $-0.271-0.448$ & & \\
\hline \multicolumn{6}{|c|}{ Psychosocial domain (PS) } \\
\hline SF-12 MCS & -0.029 & 0.001 & -0.036 to -0.023 & 0.879 & MCS: PS $=-0.436$ \\
\hline Age & -0.008 & 0.444 & $-0.029-0.013$ & & Age: $P S=-0.012$ \\
\hline Diabetes & 0.310 & 0.059 & $-0.011-0.629$ & & \\
\hline Education & -0.048 & 0.764 & $-0.366-0.269$ & & \\
\hline \multicolumn{6}{|c|}{ Physical domain (PHS) } \\
\hline SF-12 PCS & -0.026 & 0.001 & -0.031 to -0.022 & 0.804 & PCS: PHS $=-0.497$ \\
\hline Age & -0.007 & 0.442 & $-0.026-0.012$ & & Age: $\mathrm{PHS}=0.045$ \\
\hline Diabetes & -0.185 & 0.217 & $-0.479-0.109$ & & \\
\hline Education & -0.082 & 0.576 & $-0.372-0.207$ & & \\
\hline \multicolumn{6}{|c|}{ Vaginal sexual domain (VSS) } \\
\hline Marital status ${ }^{\ddagger}$ & -0.482 & 0.006 & -0.822 to -0.142 & 0.937 & Age: VSS $=-0.165$ \\
\hline Age & -0.010 & 0.394 & $-0.033-0.129$ & & \\
\hline Diabetes & -0.048 & 0.373 & $-0.388-0.293$ & & \\
\hline Education & 0.337 & 0.054 & $-0.006-0.679$ & & \\
\hline
\end{tabular}

PCS, physical component score; MCS, mental component score

*, Diabetes refers diabetes or no diabetes $(1=$ diabetes; $0=$ no diabetes $) ;{ }^{\dagger}$, education was measured as $1=$ primary schooling or lower; 2 = secondary schooling or higher; ${ }^{\ddagger}$, married $=1$; not presently married, i.e. divorced, single, widowed $=0$

are probably in the same direction to that expected, but for which the confidence intervals span negative and positive values.

Table 4 shows the results of the logistic regression analysis examining the association between depression symptoms and each of the four MENQOL domains. The odds that a woman was depressed on the CES-D scale increased 1.42 times when the MENQOL score on the psychosocial domain increased by one unit (95\% confidence interval (CI) 1.01-2.02), and the odds ratio increased 1.27 times when the MENQOL score on the physical domain increased by one unit (95\% CI 0.82-1.97).

The linear regression results also indicated that being married was associated with better quality of life on the MENQOL sexual domain; the mean sexual domain scores of married women were on average 0.482 units lower compared to those who were not married. Marital status accounted for $7 \%$ of variance in the MENQOL sexual domain scores. Women with secondary education or higher had greater quality of life complaints on the sexual domain compared to women with primary education or lower (Table 3).

The results of the logistic regression analysis examining the association between diabetes and quality of life, as determined by each of the four MENQOL domains, can be found in Table 5. The odds of presence or absence of diabetes increased
1.13 times when the MENQOL score on the psychosocial domain increased by one unit (95\% CI 0.92-1.39), and the odds ratio increased 0.99 times when the MENQOL score on the physical domain increased by one unit (95\% CI 0.80-1.22). However, none of them were statistically significant.

For symptoms associated with both diabetes and postmenopausal stage, diabetes subjects had significantly higher mean scores compared to control subjects (Table 6). Of the three vasomotor symptoms, i.e. night sweats, hot flushes and sweating, only hot flushes were significantly higher in control subjects.

\section{DISCUSSION}

The MENQOL questionnaire appears to be reliable and valid instrument based on good internal consistency and significant correlations with validated instruments. As a first study to explore the validity of a MENQOL measure in a sample of postmenopausal women with diabetes who completed the MENQOL, a quality-of-life measure developed and validated for both younger and older postmenopausal women, this study provides support for the validity of the MENQOL domains in women with diabetes. The MENQOL domains 
Table 4 Results of logistic regression analyses with depression symptoms as the dependent variables and the Menopause-specific Quality of Life (MENQOL) domains, age, education, diabetes, and marital status as the independent variables $(n=337)$

\begin{tabular}{|c|c|c|c|c|}
\hline Depression" & $\begin{array}{c}\text { Odds ratio point } \\
\text { estimates }\end{array}$ & $p$ Value & $\begin{array}{c}95 \% \text { confidence } \\
\text { interval }\end{array}$ & Variance $R^{2}$ \\
\hline Vasomotor domain & 1.22 & 0.252 & $0.87-1.70$ & 0.018 \\
\hline Age & 1.01 & 0.818 & $0.92-1.12$ & \\
\hline Diabetes & 0.67 & 0.585 & $0.16-2.77$ & \\
\hline Education & 1.26 & 0.768 & $0.27-5.92$ & \\
\hline Marital status & 1.66 & 0.467 & $0.42-6.56$ & \\
\hline Psychosocial domain & 1.42 & 0.050 & $1.01-2.02$ & 0.050 \\
\hline Age & 1.01 & 0.780 & $0.92-1.12$ & \\
\hline Diabetes & 0.59 & 0.466 & $0.15-2.41$ & \\
\hline Education & 1.42 & 0.658 & $0.30-6.75$ & \\
\hline Marital status & 1.73 & 0.438 & $0.44-6.89$ & \\
\hline Physical domain & 1.27 & 0.289 & $0.82-1.97$ & 0.022 \\
\hline Age & 1.01 & 0.864 & $0.92-1.12$ & \\
\hline Diabetes & 0.64 & 0.534 & $0.16-2.62$ & \\
\hline Education & 1.34 & 0.711 & $0.28-6.35$ & \\
\hline Marital status & 1.66 & 0.470 & $0.42-6.62$ & \\
\hline Vaginal sexual domain & 1.23 & 0.246 & $0.87-1.72$ & 0.023 \\
\hline Age & 1.01 & 0.840 & $0.92-1.12$ & \\
\hline Diabetes & 0.66 & 0.563 & $0.16-2.65$ & \\
\hline Education & 1.18 & 0.836 & $0.25-5.64$ & \\
\hline Marital status & 1.91 & 0.369 & $0.47-7.86$ & \\
\hline
\end{tabular}

*, Depression was measured with CESD-10: depressed $=1$; not depressed $=0$

were significantly associated with the well validated and widely used CES-D and SF-36 MCS scales, supporting the construct validity of MENQOL for use among women with diabetes. Our observations also revealed that the MENQOL questionnaire is an easy-to-administer instrument for measuring menopausal symptoms.

The results provide evidence supporting the reliability of the MENQOL questionnaire for use among diabetes subjects. Values of Cronbach's $\alpha$ for the sexual, physical, vasomotor and psychosocial domains were $0.79,0.86,0.70$, and 0.79 , respectively. The full MENQOL scale had a high internal consistency of 0.90, suggesting that 29 items included in the instrument are reliable. Cronbach's $\alpha$ was more than 0.80 for both diabetes and control subjects. These values of $\alpha$ are comparable with those reported in a previous study ${ }^{21}$. An interesting finding of this study is the four-factorial model of the MENQOL, similar to the ones reported earlier ${ }^{21}$, where the items loaded fully on the four factors, confirming the psychometric properties of MENQOL for use among women with diabetes. However, few items were cross-loaded on more than one domain. Consistent with the development of the scale, it is encouraging that items overwhelmingly operate in the way that they were intended.

The validity of the MENQOL psychosocial and physical domains was demonstrated through strong relationships with the equivalent SF-12 mental and physical component scales. Our results indicated that better SF-12 MCS and PCS scores were significantly related to lower psychosocial and physical symptoms of the MENQOL. These results remained significant even when the covariates of age, education, and diabetes were included in the regression models. Interestingly, diabetes was not a significant covariate and did not change the association between SF-12 component scales and MENQOL physical and psychosocial domains, suggesting that presence or absence of diabetes does not change the quality-of-life measures on the MENQOL instrument.

Three domains on the MENQOL (vasomotor, physical and sexual domains) did not predict the risk of depressive symptoms. Consistent with a previous study, the psychosocial domain of the MENQOL did predict the likelihood of symptoms of depression ${ }^{22}$. This particular finding is important because the psychosocial domain consists of items measuring the influence of depressive symptoms, providing validity to the psychosocial domain of the MENQOL. This finding may be useful in a clinical setting as responses to MENQOL may suggest concurrent problems of depression.

Our observations also revealed that diabetes subjects had significantly higher mean scores compared to non-diabetes subjects for symptoms associated with both diabetes and the postmenopausal period. However, none of the domains on the MENQOL scale predicted the likelihood of diabetes. The study has also shown that the mean ages of occurrence of menopause in women with and without type 2 diabetes are not significantly different (49.35 vs. 48.87 years). However, more women with diabetes had attained menopause compared 
Table 5 Results of logistic regression analyses with diabetes as the dependent variable and the Menopausespecific Quality of Life (MENQOL) domains, age, education, and marital status as the independent variables $(n=337)$

\begin{tabular}{lcccc}
\hline Diabetes* & $\begin{array}{c}\text { Odds ratio point } \\
\text { estimates }\end{array}$ & p Value & $\begin{array}{c}95 \text { confidence } \\
\text { interval }\end{array}$ & ${\text { Variance } R^{2}}^{\text {Vasomotor domain }}$ \\
Age & 0.93 & 0.460 & $0.78-1.12$ & 0.177 \\
Marital status ${ }^{\ddagger}$ & 1.11 & 0.001 & $1.06-1.17$ & \\
Education $^{\dagger}$ & 1.15 & 0.698 & $0.57-2.32$ & \\
Psychosocial domain & 0.16 & 0.001 & $0.10-0.39$ & 0.179 \\
Age & 1.13 & 0.249 & $0.92-1.39$ & \\
Marital status & 1.11 & 0.001 & $1.06-1.17$ & 0.175 \\
Education & 1.17 & 0.666 & $0.58-2.36$ & \\
Physical domain & 0.16 & 0.001 & $0.10-0.40$ & \\
Age & 0.99 & 0.923 & $0.80-1.22$ & \\
Marital status & 1.11 & 0.001 & $1.06-1.17$ & \\
Education & 1.16 & 0.686 & $0.58-2.33$ & \\
Vaginal sexual domain & 0.15 & 0.001 & $0.10-0.39$ & \\
Age & 0.96 & 0.686 & $0.81-1.15$ & \\
Marital status & 1.11 & 0.001 & $1.06-1.17$ & \\
Education & 1.13 & 0.741 & $0.55-2.30$ & \\
\hline
\end{tabular}

*, Diabetes refers diabetes or no diabetes $\left(1=\right.$ diabetes; $0=$ no diabetes); ${ }^{\dagger}$, education was measured as $1=$ primary schooling or lower; $2=$ secondary schooling or higher; ${ }^{\ddagger}$, married $=1$; not presently married, i.e. divorced, single, widowed $=0$

to women without diabetes $(37.7 \%$ vs. $15.0 \%, p=0.001)$. The age of onset of menopause in this study is comparable with that reported in previous studies ${ }^{27,39-41}$. It should be noted that the menopausal state may be a potential risk factor for the development of metabolic syndrome ${ }^{42}$ which could subsequently lead to diabetes.

\section{Overlap of symptoms}

Women with diabetes had significantly higher mean scores for the MENQOL symptoms or items that could be confounded with the symptoms of diabetes or poorly controlled diabetes compared to women without diabetes; we did not find significant differences for any of the MENQOL domains. This finding suggests that MENQOL can be administered in a population with diabetes. The instruments used for screening depression symptoms also contained some items that could be confounded with symptoms of diabetes or poorly controlled diabetes ${ }^{43}$. For example, questions relating to symptoms such as loss of appetite and restless sleep (which may also be related to symptoms of diabetes) are included in the CES-D scale ${ }^{35}$.

\section{Limitations}

Although we applied systematic sampling, participants who frequently attended the outpatient clinics were more likely to

Table 6 Means and 95\% confidence interval (CIs) of Menopause-specific Quality of Life (MENQOL) symptoms, associated with both diabetes and postmenopausal stage $(n=337)$

\begin{tabular}{|c|c|c|c|c|c|}
\hline \multirow[b]{2}{*}{ Items } & \multicolumn{2}{|c|}{ Diabetes } & \multicolumn{2}{|c|}{ Control } & \multirow[b]{2}{*}{ p Value } \\
\hline & Mean & $95 \% \mathrm{CI}$ & Mean & $95 \% C I$ & \\
\hline Feeling depressed, down or blue & 2.53 & $2.26-2.80$ & 1.88 & $1.55-2.22$ & 0.008 \\
\hline Feeling anxious or nervous & 2.27 & $2.02-2.52$ & 1.76 & $1.46-2.05$ & 0.023 \\
\hline Difficulty sleeping & 3.02 & $2.68-3.36$ & 2.33 & $1.89-2.78$ & 0.026 \\
\hline Feeling tired or worn out & 3.99 & $3.68-4.29$ & 3.07 & $2.67-3.48$ & 0.001 \\
\hline Feeling a lack of energy & 3.77 & $3.46-4.10$ & 2.43 & $2.10-2.77$ & 0.001 \\
\hline Dry skin & 2.63 & $2.35-2.91$ & 2.49 & $2.13-2.85$ & 0.581 \\
\hline Frequent urination & 2.52 & $2.23-2.80$ & 2.00 & $1.67-2.33$ & 0.039 \\
\hline Avoiding intimacy & 1.64 & $1.42-1.85$ & 1.48 & $1.28-1.68$ & 0.411 \\
\hline
\end{tabular}


be sampled than those who attended less frequently, and therefore were presumed to have better quality of life. This might have introduced selection bias. This study is further limited by indirect validation of the sexual domain against marital status. This is based on the expectation that married women would be more bothered by the menopausal symptoms of this domain 22,34 . There may have been participant recall bias which would be a systematic error resulting from lack of completeness of memory of past events or experiences, which may have affected accuracy of self-reported information.

\section{CONCLUSION}

The MENQOL questionnaire appears to be reliable and valid instrument based on good internal consistency and significant correlations with validated instruments. This finding confirms the construct validity of MENQOL and it was found to be a valid measure to examine quality of life in postmenopausal women with diabetes. All four domains on the MENQOL did not predict the risk of diabetes. However, it should be noted that symptoms associated with both diabetes and the postmenopausal phase had significantly higher mean scores in diabetes subjects compared to control subjects. The psychosocial domain was significantly associated with depression, suggesting that scores on this domain of the MENQOL may be indicators of depression symptoms.

Conflict of interest The authors report no conflict of interest. The authors alone are responsible for the content and writing of this paper.

Source of funding Nil.

\section{References}

1. Wild S, Roglic G, Green A, Sicree R, King H. Global prevalence of diabetes: estimates for the year 2000 and projections for 2030. Diabetes Care 2004;27:1047-53

2. Roglic G, Unwin N, Bennett PH, et al. The burden of mortality attributable to diabetes: realistic estimates for the year 2000 . Diabetes Care 2005;28:2130-5

3. Letchuman GR, Wan Nazaimoon WM, Wan Mohamad WB, et al. Prevalence of diabetes in the Malaysian National Health Morbidity Survey III 2006. Med J Malaysia 2010;65:173-9

4. National Health Morbidity Survey 1996: Diabetes. Volume 9. Institute for Public Health, Ministry of Health, Malaysia

5. Shaw JE, Sicree RA, Zimmet PZ. Global estimates of the prevalence of diabetes for 2010 and 2030. Diabetes Res Clin Pract 2010;87:4-14

6. Roumain J, Charles MA, De Courten MP, et al. The relationship of menstrual irregularity to type 2 diabetes in Pima Indian women. Diabetes Care 1998;21:346-9

7. Solomon CG, Hu FB, Dunaif A, et al. Long and highly irregular menstrual cycles as a marker for risk of type 2 diabetes mellitus. JAMA 2001;286:2421-6

8. Rubin RR, Peyrot M. Quality of life and diabetes. Diabetes Metab Res Rev 1999;15:205-18

9. Landman GW, van Hateren KJ, Kleefstra N, Groenier KH, Gans RO, Bilo HJ. Health-related quality of life and mortality in a general and elderly population of patients with type 2 diabetes (ZODIAC-18). Diabetes Care 2010;33:2378-82

10. Kleefstra N, Landman GW, Houweling ST, et al. Prediction of mortality in type 2 diabetes from health-related quality of life (ZODIAC-4). Diabetes Care 2008;31:932-3

11. Fuh JI, Wang SJ, Lu SR, Juang KD, Chiu LM. The Kinmen Women-health Investigation (KIWI): a menopausal study of a population aged 40-54. Maturitas 2001;39:117-24

12. Harvey C, Bee HT, Chia CA, Ee MC, Yap SC, Seang MS. The prevalence of menopausal symptoms in a community in Singapore. Maturitas 2002;41:275-82

13. Bastian LA, Smith CM, Nanda K. Is this woman perimenopausal? JAMA 2003;289:895-902

14. Williams RE, Levine KB, Kalilani L, Lewis J, Clark RV. Menopause-specific questionnaire assessment in US populationbased study shows negative impact on health-related quality of life. Maturitas 2009;62:153-9
15. Hilditch J, Lewis J, Peter A, et al. A menopause-specific quality of life questionnaire: development and psychometric properties. Maturitas 1996;24:161-75

16. Brzyski R, Medrano M, Hyatt-Santos J, et al. Quality of life in low income menopausal women attending primary care clinics. Fertil Steril 2001;76:44-50

17. Chedraui P, Hidalgo L, Chavez D, et al. Menopausal symptoms and associated risk factors among postmenopausal women screened for the metabolic syndrome. Arch Gynecol Obstet 2007;275:161-8

18. Alwi SARS, Lee PY, Awi I, Mallick PS, Haizal MNM. The menopausal experience among indigenous women of Sarawak, Malaysia. Climacteric 2009;12:548-56

19. Oddens BJ, Boulet MJ, Lehert P, Visser AP. Has the climacteric been medicalised? A study on the use of medication for climacteric complaints in four countries. Maturitas 1992; 15:171-81

20. Boulet MJ, Oddens BJ, Lehert P, Verme HM, Visser AP. Climacteric and menopause in seven South-east Asian countries. Maturitas 1994;19:157-76

21. Van Dole KB, DeVellis RF, Brown RD, Funk MLJ, Gaynes BN, Williams RE. Evaluation of the Menopause-Specific Quality of Life Questionnaire: a factor-analytic approach. Menopause 2012;19:211-15

22. Kulasingam S, Moineddin R, Lewis JE, Tierney MC. The validity of the menopause specific quality of life questionnaire in older women. Maturitas 2008;60:239-43

23. Hasan SS, Clavarino AM, Mamun AA, Doi SAR, Kairuz T. Population impact of depression either as a risk factor or consequence of type 2 diabetes in adults: A meta-analysis of longitudinal studies. Asian J Psychiatry (2013), http://dx.doi.org. ezproxy.library.uq.edu.au/10.1016/j.ajp.2013.09.008

24. Engum A. The role of depression and anxiety in onset of diabetes in a large population-based study. J Psychosomatic Res 2007; 62:31-8

25. Meisinger C, Heier M, Loewel H. Sleep disturbance as a predictor of type 2 diabetes mellitus in men and women from the general population. Diabetologia 2005;48:235-41

26. Global guideline for type 2 diabetes. International Diabetes Federation: clinical guidelines task force (2005), at http://www.idf. org/webdata/docs/IDF\%20GGT2D.pdf 
27. Ogbera A, Fasanmade O, Kalra S. Menopausal symptoms and the metabolic syndrome in Nigerian women with type 2 diabetes mellitus. Climacteric 2011;14:75-82

28. Testa MA, Simonson DC. Health economic benefits and quality of life during improved glycemic control in patients with type 2 diabetes mellitus: a randomized, controlled, double-blind trial. JAMA 1998;280:1490-6

29. Maurischat C, Herschbach P, Peters A, Bullinger M. Factorial validity of the short form (SF-12) in patients with diabetes mellitus. Psychol Sci Q 2008;50:7-20

30. Sundaram M, Kavookjian J, Patrick JH, Miller LA, Madhavan SS, Scott V. Quality of life, health status and clinical outcomes in type 2 diabetes patients. Qual Life Res 2007;16:165-77

31. Schunk M, Reitmeir P, Schipf S, et al. Health-related quality of life in subjects with and without type 2 diabetes: pooled analysis of five population based surveys in Germany. Diabetic Med 2012;29:646-53

32. Ware JE, Kosinski M, Keller SD. A 12-item short-form health survey: construction of scales and preliminary tests of reliability and validity. Med Care 1996;34.220-33

33. Ware JE, Kosinski M, Keller SD. SF-36 Physical and Mental Health Summary Scales: A User's Manual. Boston: The Health Institute, New England Medical Center, 1994

34. Gott M, Hinchliff S. How important is sex in later life? The views of older people. Soc Sci Med 2003;56:1617-28
35. Radloff LS. The CES-D scale: A self report depression scale for research in the general population. Applied Psychol Measurement 1978;1:385-401

36. Swenson SL, Rose M, Vittinghoff E, Stewart A, Schillinger D. The influence of depressive symptoms on clinician-patient communication among patients with type 2 diabetes. Med Care 2008;46:257-65

37. Brockington I. Motherhood and Mental Illness. Oxford: Oxford University Press, 1996

38. Kempen GI, Brilman EI, Ranchor AV, Ormel J. Morbidity and quality of life and the moderating effects of level of education in the elderly. Soc Sci Med 1999;49:143-9

39. Ozumba BC, Obi SN, Obikili E, Waboso E. Age symptoms and perception of menopause among Nigerian women. J Obstet Gynecol 2004;54:575-8

40. Lopez-Lopez R, Raquel H, Malacara JM. Age at menopause in type 2 diabetes mellitus. Menopause 1999;6:2

41. Palmer JR, Rosenberg L, Wise LA, Horton NJ, Adams-Campbell LL. Onset of natural menopause in African American women. Am J Public Health 2003;93:299-306

42. Petri Nahas EA, Padoani NP, Nahas-Neto J, Orsatti FL, Tardivo AP, Dias R. Metabolic syndrome and its associated risk factors in Brazilian postmenopausal women. Climacteric 2009;12:431-8

43. Roy T, Lloyd CE, Pouwer F, Holt RIG, Sartorius N. Screening tools used for measuring depression among people with type 1 and type 2 diabetes: a systematic review. Diabetic Med 2012;29:164-75 
Copyright of Climacteric is the property of Taylor \& Francis Ltd and its content may not be copied or emailed to multiple sites or posted to a listserv without the copyright holder's express written permission. However, users may print, download, or email articles for individual use. 